\title{
EL PAPEL DEL PROFESIONAL DE LAS RELACIONES PÚBLICAS EN LA ADMINISTRACIÓN DE LA CONTROVERSIA PÚBLICA
}

\author{
AUTOR \\ Luis Solano Fleta \\ Catedrático de Universidad Complutense de Madrid (España). \\ Isfleta@yahoo.es
}

\section{RESUMEN}

Este artículo pretende determinar el papel que desempeña el profesional de las Relaciones Públicas en la denominada controversia pública, donde se hallan involucradas las principales razones nucleares de la profesión, pese a que se ha avanzado poco en la comprensión conceptual de esta y de sus profesionales. Además, buscamos definir este papel debido al creciente grado de polémica social suscitada por los acontecimientos políticos, que ha llevado a una comprensión deficiente del papel de los gabinetes de prensa y de sus trabajadores desde el punto de vista las definiciones tradicionales de Relaciones públicas. De esta forma dejaremos determinadas las funciones de dichos departamentos, en comparación con gabinetes o instituciones que hayan podido ser considerados equivalentes en funciones, y cuya descripción resulta en confusión conceptual perjudicial para las labores de estudio académico y profesional. Estableceremos igualmente las analogías laborales adecuadas, pertinentes para la comprensión global de la materia, y la definición correcta de controversia pública en su relación con el de opinión pública y sus implicaciones actuales, así como la forma en la que el profesional de la comunicación debe percibir estos elementos para satisfacer sus obligaciones.

\section{PALABRAS CLAVE}

Relaciones Públicas - Profesional - Administración - Controversia pública - Opinión Pública

\section{Introducción.}

El asunto sobre el que versa la siguiente investigación, es decir, el papel de las Relaciones Públicas en la denominada controversia pública, reúne las principales cuestiones nucleares de la profesión publirrelacionista.

En primer lugar, el concepto de Relaciones Públicas, punto de encuentro obligado de todas las discusiones sobre las mismas.

En segundo término, el concepto de administración, concepto que es todo menos pacífico, como vamos a tener ocasión de ver enseguida.

En tercer lugar, la idea de controversia pública, que nos remite al concepto de opinión pública, de una parte y al papel que desempeñan los medios de comunicación social en nuestras sociedades, de otra.

Por último, la dimensión exacta de eso que se denomina, con legitimado barbarismo, profesionalidad, cuya repercusión en nuestras tareas y funciones es, sencillamente, 
superlativa. Examinemos, a continuación, los aspectos más relevantes de las ideas avanzadas.

\section{Concepto de Relaciones Públicas.}

Naturalmente, no voy a cansar al lector repitiendo una vez más los conceptos tradicionales de Relaciones Públicas, siquiera a los más de nosotros se nos antoje que, por circunstancias que vienen al caso, su concepto diste mucho de hallarse plenamente delimitado, manteniéndose en equilibrio inestable entre los requerimientos técnicos de la sociedad -atenta sólo a la satisfacción de sus necesidades de comunicación- y ese pensamiento de más altos vuelos cuyo horizonte es el profeso humano.

Pero ¿qué son las Relaciones Públicas?

Prescindamos de planteamientos teóricos y abordemos, por unos instantes, la cuestión, desde un punto de vista estrictamente funcional, es decir, trazando las funciones típicas de un departamento de Relaciones Públicas:

"La función del departamento es la de ser un trampolín para las preocupaciones de la base. El departamento identifica las cuestiones, averigua su relación con la empresa y desarrolla las correspondientes normas. El departamento debe estar emplazado en la cúspide del poder empresarial. A este ejecutivo se le encarga un objetivo de la empresa que se puede exponer sin trabas: crear y gestionar la capacidad de ésta para adaptarse a su entorno social"

La cita no corresponde, paradójicamente, a un experto o profesional de las Relaciones Públicas, sino a James F. Langton, Senior Vicepresidente del Social Policy Departament del Bank of America, quien se refiere, claro está, a las funciones de un departamento social, no de Relaciones Públicas.

Pero, continuemos con Langton:

“...el departamento proporciona a la Dirección y al Consejo una identificación inmediata y el análisis de temas y tendencias sociales, incluyendo las necesidades de las bases y sus relaciones con la empresa, elabora una conducta de la empresa nueva o revisada, programas, posiciones, planes y normas, y desarrolla los sistemas de evaluación de la eficacia social y del coste-eficacia de los cambios realizados".

Recomienda a la Dirección la información a difundir y los métodos de difusión, para que las bases de la empresa puedan evaluar el rendimiento de la misma. Se encarga de que el diálogo se mantenga con las bases... está encargado del análisis de la conducta de la empresa para asegurar su continua adecuación, y recomienda políticas según las necesidades y exigencias del ambiente externo.

Pese a que Langton lo ignora 0 , mejor dicho, lo quiere ignorar, las misiones y funciones descritas son las propias, o deben ser las propias, de un departamento de Relaciones Públicas y desde luego, no constituyen novedad alguna en el ámbito de nuestra actividad, porque ya hace unas cuantas décadas las Relaciones Públicas abordaron el problema de la llamada responsabilidad social de los entes colectivos 
formales, aunque también es cierto que, entonces, recibieron una vez más otra denominación: asuntos públicos.

A tenor de lo que hemos examinado hasta el momento, ya estamos en condiciones de contestar a la pregunta acera de qué son o en qué consisten las Relaciones Públicas: aquélla actividad que tiene por objeto la realización de procesos de comunicación intragrupales e intergrupales, generalmente vehiculados en los llamados principios rectores del contenido material de los mismos, en tanto en cuanto dichos procesos tengan por finalidad la gestación de actitudes de solidaridad hacia el sujeto individual o colectivo que los inicia y mantiene.

La determinación puntual del concepto exige la inclusión de otro ingrediente esencial: las Relaciones Públicas no se agotan en la realización de procesos de comunicación gestores de actitudes de solidaridad, sino que comprenden también la dimensión formal de todos los restantes, en otras palabras, las Relaciones Públicas afectan totalitariamente a todos los procesos de comunicación -formalmente, a todos ellos, formal y sustantivamente, a los que se enderezan de modo directo e inmediato a gestar actitudes de solidaridad social-.

\section{Concepto de Administración}

La segunda cuestión planteada era la relativa al concepto de administración, supuesto que el profesional de las Relaciones Públicas participa de algún modo en la llamada administración de la controversia pública.

Lo primero que cabe decir al respecto es que el término administración, en el sentido en que se utiliza aquí y ahora -esto es, referido ala controversia pública- se corresponde plenamente con su significado etimológico: acción y efecto de administrar, es decir, de ofrecer a otro o servirle alguna cosa, "ad manus trahere", y para mayor precisión, "traer en la mano".

¿Qué es lo que el profesional de las Relaciones Públicas ofrece o sirve a otro? Y de otra parte ¿quién es ese otro, a quien oteamos en la pleamar de nuestra tarea?

Recordemos que se trata e una controversia publica, esto es, de una discusión larga y minuciosa en la comunidad o colectividad y sobre cuestiones respecto de las cuales la "norma de cultura" exige un pronunciamiento urgente y rotundo.

Pero, sucede que hemos pasado de puntillas por la idea encapsulada en el término "pública" y que esta expresión contiene germinalmente una formidable capacidad polémica.

Por lo pronto, el término "pública" o "público" es un adjetivo calificativo, pero también un sustantivo, en otras palabras, "lo público" se ha convertido en "el público". ¿Y quién es el público?

Rovigatti nos dirá, al respecto, que:

"el público no es sino un conjunto de individuos privados, considerados en particular como opuestos o contraparte de lo que es público; de hecho, el público no coincide ni con el pueblo ni con la población, siendo en realidad una parte de ella, a saber, aquella parte que se interesa en un hecho, una situación, un servicio, etc., y asume juicios, actitudes y aun comportamientos." 
Pero, es, sin duda, De Souza Andrade, quien ha subrayado muy bien las características del fenómeno:

- $\quad$ Agrupación espontánea.

- Reunión de individuos o de grupos organizados, independiente de las limitaciones geográficas.

- $\quad$ Existencia de una controversia.

- $\quad$ Presencia de desacuerdo o de oposición.

- Posibilidad de discusión.

- Abundancia de informaciones.

- Predominio de la crítica y de la reflexión

- Búsqueda de una opción y de una actitud comunes.

Una síntesis de ambas posiciones y su posterior configuración como ingrediente complementario de la controversia nos permitiría arriesgar el siguiente concepto de controversia pública:

“Discusión larga y minuciosa entre agrupaciones espontáneas de individuos o de grupos organizados, privados que, estando en posesión de una información abundante respecto del tema objeto de la disputa, buscan, a través de la crítica y la reflexión, el surgimiento de una actitud común."

¿Y qué papel desempeña en todo esto el profesional de las Relaciones Públicas, o dicho con otras palabras, qué es lo que ofrece o sirve al público?

La respuesta a esta pregunta es muy sencilla: información. Pero, se nos objetará que, entonces, nuestros profesionales no difieren, en absoluto, de los restantes profesionales de la comunicación, entiéndase, periodistas, publicitarios, agentes de prensa, etc.

¿Dónde estriba, por tanto, la diferencia? En la peculiar finalidad de la información suministrada que, respetando plenamente el principio de veracidad, ofrece al público.

interesado la singular interpretación de los hechos controvertidos que mantiene la parte cuya representación ha asumido.

Compórtese el profesional de Relaciones Públicas, en lo tocante a este punto, de modo análogo a como lo hace el abogado de cada una de las partes en el ámbito jurídico - procesal, actuación que, como es sabido, le convierte en colaborador de la justicia, lo que legitima su postura, haciéndola imprescindible en el foro.

No se nos oculta que las ideas que mantenemos involucran una concepción de los medios de comunicación social o, mejor dicho, del sistema de comunicación pública que lo configura como un servicio público, concepción sujeta a controversia y desde luego, rechazada por ciertos sectores ius-administrativistas. No obstante, nosotros la asumimos plenamente, dada la importancia que tiene en el mundo actual la información. 
Pero, observemos que se habla de "administración de la controversia pública" y que, de acuerdo con lo que afirmábamos antes, el publirrelacionista se nos presenta como un mero colaborador de un organismo superior, que es en última instancia, el que administra la controversia, o lo que es igual, el que a la postre formula el juicio definitivo sobre la cuestión controvertida, después de haber ponderado los puntos de vista de las partes en litigio.

¿Cuál es ese órgano?: Sencillamente, la comunidad o colectividad no implicada en la controversia, el conjunto de los ciudadanos, que observa la contienda y que, tras la crítica y la reflexión de las razones aducidas, formulará su juicio definitivo: esto es, la interpretación de los hechos de acuerdo con la norma de cultura.

\section{- La controversia pública: opinión pública y el papel de los medios de comunicación social.}

Casi sin darnos cuenta, hemos entrado de lleno en la tercera de las reflexiones que proponíamos inicialmente, la controversia pública, que nos lleva en derechura, como dijimos más arriba, a dos cuestiones cardinales: la opinión pública y el papel que desempeñan los llamados medios de comunicación social en nuestra sociedad.

Por lo que respecta a la opinión pública, resultaría perfectamente inútil por nuestra parte subrayar su importancia en el ámbito propio de nuestras actividades y saberes; ilustres tratadistas lo han hecho ya: así, verbigracia, Canfield, quien afirmó tajantemente:

"El objetivo esencia de las Relaciones Públicas es el de moldear la opinión pública e influir sobre ella. En consecuencia, es importante que quienes practican las Relaciones Públicas comprendan la formación, naturaleza, desarrollo y significado de la opinión pública".

Y Moore, quien no vacilaba en sostener que: "El objetivo de las Relaciones Públicas es el desarrollo de una opinión pública favorable hacia una institución social, económica o política.” A mayor abundamiento, Cutlip y Center consideran que:“La misión del profesional de las Relaciones Públicas es la de influir en la opinión pública".

Ahora bien, una cosa es reconocer la importancia de un fenómeno y otra bien distinta delimitar con precisión sus fronteras respecto de otros de naturaleza más o menos análoga, porque sucede que la opinión pública es un fenómeno sumamente difícil de aprehender conceptualmente, hasta el punto de haberse llegado a afirmar, como hace, sin ir más lejos, Stoetzel, que:“...es una expresión lenguaje vulgar y no es seguro que le corresponda una realidad de la cual se pueda definir la estructura ni marcar las fronteras".

O Noelle Neuman, quien sostiene que: “...el término "opinión pública” corresponde a una realidad, pero las explicaciones no han acertado todavía a determinar dicha realidad"

¿Hasta qué punto responden a la realidad las cautelas de la doctrina al respecto? Cierto que se trata, ya inicialmente, de una expresión polisémicas, como ha advertido magistralmente Rovigatti; cierto, asimismo, que existen numerosas definiciones 0 , mejor, intentos de definición del fenómeno, algunos de los cuales no sólo son diversos sino incluso antagónicos... Pero, no lo es menos que, en la mayoría de los supuestos contemplados por los autores, no se alude tanto a las 
características intrínsecas del fenómeno cuanto a los factores que intervienen en su formación; esto es, a lo que antes denominábamos "controversia pública". Dice, en efecto, Monzón, citando a González Seara:

“...es muy poco lo que sabemos acerca del proceso de la opinión pública y, entre los factores que intervienen, cita la personalidad individual, la naturaleza de Iso grupos, la estructura social del país de referencia, los sistemas educativos imperantes, la acción de los medios de comunicación...".

¿Quiere ello decir que debemos renunciar a una definición acerca de qué es la opinión pública? En absoluto. Desde nuestro punto de vista, la opinión pública es, sencillamente, el pronunciamiento expreso de una colectividad a través de las personas idóneas en cada caso, acerca de un aspecto de la realidad que se considera de interés general y que ha sido objeto de controversia.

En la definición que acabamos de formular se hallan contemplados todos los ingredientes del fenómeno.

Mención especial requiere la expresión "controversia" como fenómeno previo al surgimiento de la opinión pública, porque parece ser que constituye un requisito "sine qua non", según los autores, la existencia de un punto de fricción o, si se prefiere, la ausencia de unanimidad; así, por ejemplo, Sauvy, quien afirma:

"No se habla de opinión pública cuando hay una total comunión de ideas. No habría interés en afirmar que la opinión pública se pronuncia contra los terremotos, el incesto o la poliomielitis... Para que se pueda hablar verdaderamente de opinión pública, es necesarios que haya una resistencia eficaz o, por lo menos, posible".

En nuestra opinión, postura de Sauvy y con él la de gran parte de la doctrina, obedece a la confusión entre el proceso generador de la opinión pública y ésta en cuanto tal; el proceso generador será, generalmente, controvertido, pero concluido éste, la opinión pública deviene opinión común, unánime o mayoritariamente asumida por los miembros de la colectividad. Prueba de ello se encuentra en que, como sostiene Rovigatti:

“...muchas veces la opinión pública no es el resultado de la convergencia de opiniones individuales, preexistentes, sino que nace directa e inmediatamente como la manifestación de un nosotros... sobre todo cuando se manifiesta bajo la forma de adhesión simultánea a una propuesta más que de una elaboración crítica del grupo".

De ahí, afirmamos nosotros, la importancia del papel del profesional de las Relaciones Públicas en la administración de la controversia pública; esto es, en el proceso generador de la opinión pública, único momento en que su intervención, como factor influyente -decisivo, tal vez-, tiene sentido.

Pero, aún hay más. Si la opinión pública, como dijimos antes, es el pronunciamiento expreso de una colectividad, a través de las personas idóneas en cada caso, acerca de un aspecto de la realidad que se considera de interés general y que ha sido 
objeto de controversia, en otras palabras, el pronunciamiento expreso del público, el profesional de las Relaciones Públicas, su gestor en la mayoría de los casos, hace posible, mediante su intervención, recuperar la sociedad de públicos de la tradición clásica, en la que el papel de estos conjuntos humanos tenía por finalidad, como nos recuerda Blumer: "....incitar a un debate racional de cuestiones que afectan a la colectividad".

Postura que, como habrá advertido el lector dista en gran manera de la sostenida por Habermas, cuya inquina hacía nosotros le hace incapaz de percibir que son precisamente las Relaciones Pública el único antídoto efectivo contra la progresiva masificación de nuestra sociedad.

Si la referencia al fenómeno de la controversia pública nos remitía, a la postre, al de opinión pública, no es menos cierto que también exige, el bordaje de los medios de comunicación social, so pena de mutilar arbitrariamente los conceptos, supuesto que, como nos recuerda Castillo:

"Los públicos -como cualquier otro fenómeno social no nacen por generación espontánea: su aparición y desarrollo obedecen a hondas transformaciones del tejido social, tales como: el paulatino descenso de la mortalidad, el desarrollo de la imprenta; la construcción de una red de transportes; la extensión de la alfabetización; la secularización del sistema de valores; la instauración de la democracia liberal; la difusión de la prensa periódica". Y líneas más abajo, añade: "De entro todos ellos, el progreso de la técnica cumplió un papel fundamental".

Progreso de la técnica que, en nuestro tiempo, ha sido y es sencillamente formidable. Los públicos, la sociedad de públicos, en definitiva, es la resultante de un conjunto de felices coincidencias, entre las que destaca, sobre todo, el desarrollo, o mejor, híper-desarrollo, de los llamados medios de comunicación social: la prensa, el cine, la radio, la televisión...

Ahora bien, atribuir al desarrollo técnico la gestación de una sociedad de públicos significaría ignorar que se trata sencillamente de una visión idílica y, por consiguiente, utópica, de la función que, "de facto", han desempeñado y desempeñan.

Ya Tarde, el sociólogo francés, como nos recuerda Castillo:

“...observó cómo, con la pujante expansión de la prensa, se había alterado el inestable equilibrio de fuerzas del mundo de la comunicación: frente a la directa y limitada comunicación de la palabra oral, hacía seguir ya su prestigio y poder la ubicua palabra del periódico. De aquí, que afirmase que, dada la creciente concentración de las comunicaciones en unas pocas manos, resultara muy difícil sostener la libertad e igualdad de los hombres antes los medios de comunicación de masas".

Sin negar la evidencia de las palabras de Tarde, no es menos cierto que se trata de una visión excesivamente pesimista, visión, de otro lado, anclada en un estereotipo intelectual, cuyos orígenes son diversos: la crítica de la teoría aristocrática de la sociedad de masas, concepción utópica de una era dorada, un cierto encelamiento de los intelectuales ante el poder creciente y avasallador de los medios de comunicación social... Y por qué no decirlo, la ignorancia crasa en que se 
encuentran al juzgar, con evidente menosprecio, hijo de su necedad -y utilizo la palabra en su justa acepción primeriza- las funciones y tareas de los profesionales de las Relaciones Públicas, artífices de la humanización, o mejor, rehumanización del hombre en nuestro tiempo. En nuestra condición de profesionales y docentes de las Relaciones Públicas, no compartimos tan pesimista visión de los medios de comunicación social. Antes bien, consideramos que la mal llamada comunicación de masas es, como quería Wright:

“...un tipo especial de comunicación, que involucra ciertas condiciones operacionales distintivas, principalmente acerca de cuál es la naturaleza del auditorio, de la experiencia de comunicación y del comunicador".

Siendo sus funciones, de acuerdo con $\mathrm{H}$. Laswell:

1) La supervisión del ambiente.

2) La concordancia de las partes de la sociedad en respuesta a ese ambiente.

- $\quad$ La transmisión de la herencia social de una generación a la siguiente.

Pero, por favor, no se nos interprete mal. Ni compartimos la pesimista visión de los sociólogos ni la ingenua concepción de los comunicólogos; más bien, nuestra postura traduce la aceptación de un desafía y puede resumirse en el siguiente esquema: los medios de comunicación social deben ejercer estas funciones; los medios de comunicación no siempre llevan a cabo estas funciones; nuestra función, como profesionales y docentes de las Relaciones Públicas, es lograr que, paulatinamente, los medios de comunicación se adecuen a lo que la sociedad demanda de ellos, satisfaciendo, como servicio público, las necesidades de información de esa misma sociedad; esto es, haciendo posible la realización del llamado derecho a la información.

\section{El profesional de las Relaciones Públicas.}

Y con estas reflexiones, entramos en el examen y consideración de la última de las cuestiones que inicialmente propusimos: la profesionalidad, referida, como la pupila a la luz, al ámbito que nos es propio: las Relaciones Públicas.

¿Qué es un profesional de las Relaciones Públicas?

Una corriente que, poco a poco, va abriéndose camino en la conciencia de nuestra sociedad quiere que el ejercicio de las Relaciones Públicas quede circunscrito, exclusivamente, al ámbito de la comunicación; háblase, incluso, de "comunicador profesional", soslayando la genuina denominación de Relaciones Públicas para designar ese fenómeno de interacción humana que pretende, por encima de cualesquiera otras finalidades, fortalecer la cohesión social.

Frente a esa corriente, nos encontramos los docentes y profesionales que luchamos por transcender la angosta perspectiva técnica del fenómeno.

Hace ya muchos años, escribimos:

"El término "Relaciones Públicas" ha adquirido carta de naturaleza en el vocabulario del hombre del hoy. Basta coger un periódico o revista cualquiera para advertir el extraordinario número de veces que, de un modo u otro, aparecen ambas palabras. Se podría afirmar 
que las Relaciones Públicas constituyen algo íntimamente unido a nuestro tiempo, que forma parte de nuestra vida cotidiana. Sin embargo, las Relaciones Públicas son una actividad perfectamente desconocida para gran parte del mundo, que las suele identificar con actitudes de cortesía, modales de gente bien educada y cuando más, con relaciones importantes en el mundo de la Prensa, de la Política o de los Negocios".

Casi un cuarto de siglo más tarde, las ideas esenciales subyacentes en el párrafo en cuestión continúan vigentes, sin que por desgracia se hayan experimentado grandes avances en la concepción social de un fenómeno, cuya afección a los intereses colectivos se nos antoja determinante, en gran medida, del éxito o fracaso de la cohesión y solidaridad sociales.

Sin embargo, como afirmábamos en nuestros párrafos iniciales, es muy fácil describir qué es un profesional de las Relaciones Públicas, siquiera, una vez más, se pretendan trasmutar sus genuinas funciones mediante denominaciones nuevas.

Parafraseando a Langton, podríamos trazar el perfil de nuestro profesional del modo siguiente: en primer lugar, ha de ser un experto en comunicación, pero también un perceptor clarividente de las fuerzas sociales y del proceso socio-político, naturalmente, debe tener una plena comprensión de los beneficios que supone para la sociedad la institución o la empresa cuyos intereses defiende, pero también de que la supervivencia de las misma depende de que cumpla, y parezca que está cumpliendo, una necesidad legítima de la sociedad y de una forma legítima. Al propio tiempo, ha de tener una gran capacidad para soportar la ambigüedad porque necesariamente topará con las dudas inherentes en todo proceso de índole social y porque aún después de concretar los temas, las decisiones referentes a los mismos raramente pueden ser claras y tajantes. Debe estar dispuesto a asumir el papel de defensor de los grupos sociales relacionados con la empresa o institución, consciente de que este papel puede llegar a hacerse institucionalmente difícil, lo que le exigirá una especial preparación psicológica que le permita mantener una distancia emocional respecto de su identificación con la empresa o institución de que se trate.

Pero, no quiero cansar más al lector, repitiendo lo que sabe perfectamente en el fuero de su conciencia.

A fin y al cabo, si nuestra profesión se hubiera forjado en Roma, habría estado, sin duda, bajo el divino patrocinio de Jano, la diosa de las dos caras, una de las cuales atendería, simbólicamente, a los requerimientos, perfectamente legítimos y desde luego, eminentes, de la sociedad. De ahí que, el profesional de las Relaciones Públicas deba configurarse, ante la organización de que depende, como el gestor o mandatario de los intereses sociales, y antes la sociedad de las que forma parte, como el defensor de los legítimos intereses de su empresa o institución. Sólo así cumplirá con su deber; sólo así podrá ser considerado un profesional de las Relaciones Públicas.

\section{BIBLIOGRAFÍA}

DE SOUZA ANDRADE, C. T. (1977): Application aux relations publiques du concept de public. Montreal. 
LANGTON, J. F. (1982): El valor social de la Empresa: Razones y Causas. Ed. Banco de Bilbao. Madrid.

MOORE, S. M. y CANFIELD, B. R. (1980): Relaciones Públicas. CECSA. México.

WRIGHT, R. (1963): Comunicación de masas. Paidós. Buenos Aires. 